\title{
Nervous system effects of dissolved and nanoparticulate cadmium in rats in subacute exposure
}

\author{
Edina Horváth, ${ }^{a}$ Gábor Oszlánczi, ${ }^{a}$ Zsuzsanna Máté, ${ }^{a}$ Andrea Szabó, ${ }^{a}$ \\ Gábor Kozma, ${ }^{b}$ András Sápi, ${ }^{b}$ Zoltán Kónya, ${ }^{b}$ Edit Paulik, ${ }^{a}$ \\ László Nagymajtényi ${ }^{\mathrm{a}}$ and András Papp ${ }^{\mathrm{a} *}$
}

\begin{abstract}
Cadmium, a toxic heavy metal with various applications in technology, can affect people both by environmental (foodborne) and occupational (inhalation) exposure and can cause nervous system damage. To model this, rats were subacutely treated either with $\mathrm{CdCl}_{2}$ solution per os $\left(3.0 \mathrm{mg} \mathrm{kg}^{-1}\right.$ b.w.) or nanoparticulate $\mathrm{CdO}_{2}$ (particle size ca $\left.65 \mathrm{~nm}\right)$ by intratracheal instillation $\left(0.04 \mathrm{mg} \mathrm{kg}^{-1} \mathrm{~b} . \mathrm{w}\right.$.) alone or in sequential combination. Nervous system effects were observed at different levels of function (open field behavior, cortical electrical activity, nerve action potential) and some general toxicological indicators were also measured. Three weeks of oral plus one week of intratracheal exposure caused significant reduction of body weight gain and open field motility. Lengthening of latency of sensory evoked potentials, observed in all treated rats, was also the most significant in the group receiving oral plus intratracheal treatment. Conduction velocity of the tail nerve was likewise decreased in all treated groups. Several of the effects pointed to a potentiating interaction between the two forms of $\mathrm{Cd}$. Modeling environmental and occupational $\mathrm{Cd}$ exposure by oral and intratracheal application in rats was feasible, with results suggesting serious negative health effects in humans suffering such a combined exposure. Copyright $\odot$ 2011 John Wiley \& Sons, Ltd.
\end{abstract}

Keywords: cadmium; nanoparticle; neurotoxicity; behavioral toxicity; rat

\section{INTRODUCTION}

Cadmium is a metal which is frequently encountered in occupational and environmental settings, has no known biological function in humans, and is toxic in small amounts. Its presence in the environment (in air, soil, groundwater, etc.) is partly due to human activity. The general population is exposed mainly by contaminated drinking water or food: Cd levels in fruit, vegetables and meat can reach $10 \mu \mathrm{g} \mathrm{kg}^{-1}$, in offal (kidney and liver) they can reach $100-1000 \mu \mathrm{g} \mathrm{kg}^{-1}$ and in shellfish, 200$2000 \mathrm{~g} \mathrm{~kg}^{-1}$ (Galal-Gorchev, 1991). Cultivated plants, first of all cereals, tend to accumulate $\mathrm{Cd}$ from the soil. In areas surrounding industrial plants with high $\mathrm{Cd}$ emission, house dust can also be a noteworthy source of human exposure (Leroyer et al., 2001). Cadmium is also present in tobacco smoke: each cigarette contains about $2 \mu \mathrm{g}$ of $\mathrm{Cd}$, of which ca $50 \%$ is absorbed from the inhaled smoke in the lungs (Elinder et al., 1983).

Cadmium also enters the body mainly via inhalation of metal dust and fumes in occupational exposure. $\mathrm{Cd}$ was, and partly still is, used steel and other alloys, in pigments, in nickelcadmium batteries and in electroplating. Measured airborne levels were ca $30 \mathrm{\mu g} \mathrm{m}^{-3}$ (indoors in car body repair shops; Vitayavirasuk et al., 2005) or 1-19 $\mathrm{\mu g} \mathrm{m}^{-3}$ (outdoors, in bridge maintenance; Conroy et al., 1995). Cadmium is absorbed from the respiratory tract at $2-50 \%$, depending on the particle size, while gastrointestinal absorption is 5-20\% (Chaney et al., 2004). Absorbed $\mathrm{Cd}$ is transported via the blood to the main target organs such as kidney, liver, bones and brain (Goering et al., 1995).
Acute inhalation of Cd-containing fumes causes pulmonary edema with respiratory symptoms (dyspnea, chest tightness, metal fume fever). In a case reported by Okuda et al. (1997), acute $\mathrm{Cd}$ poisoning with respiratory signs developed, in 36 months, into a Parkinson-like state (stiffness of the limbs, bradykinesia, muscle rigidity) that did not improve with antiparkinsonian medication. Amyotrophic lateral sclerosis, optic nerve damage, striatal damage and peripheral polyneuropathy were also observed as long-term neurotoxic consequences of Cd (Bar-Sela et al., 2001; Fern et al., 1996; O'Callaghan and Miller, 1986; Viaene et al., 1999).

Natural phenomena (volcanic activity) and industrial hightemperature processes (smelting, casting, welding, cutting, grinding, etc.) generate airborne metal-containing particles, including those in the submicron range (nanoparticles, NPs). Beside the intensity of ventilation and the amount and physicochemical properties of the inhaled particles, the adverse effects in inhalational exposure depend largely on the particle size (Oberdörster et al., 2000). Compared with microscopic

*Correspondence to: A. Papp, Department of Public Health, University of Szeged Faculty of Medicine, H-6720 Szeged, Dóm tér 10., Hungary.

E-mail: ppp@puhe.szote.u-szeged.hu

${ }^{a}$ Department of Public Health, University of Szeged Faculty of Medicine, $\mathrm{H}-6720$ Szeged, Dóm tér 10., Hungary

${ }^{b}$ Department of Applied Chemistry, University of Szeged Faculty of Science and Informatics, H-6720 Szeged, Rerrich Béla tér 1., Hungary 
particles, NPs have higher mobility within the organism, including direct access to the CNS by penetrating tissue boundaries like the alveolar and capillary wall, and the bloodbrain barrier (Elder et al., 2006; Kreyling et al., 2006).

In this work, the above-mentioned general (foodborne) and occupational (inhalational) exposure was modeled by giving $\mathrm{Cd}$ to rats in two different chemical forms, and combining exposure via the airways and the gastrointestinal tract. Our aim was to study the adverse effects caused by $\mathrm{Cd}$ in different physicochemical forms by behavioral and electrophysiological methods.

\section{MATERIALS AND METHODS}

\section{Animals and Treatment}

Young adult male Wistar rats $(200 \pm 20 \mathrm{~g}, 8$ groups of 12 rats each) were obtained from the university's breeding center and were housed in a GLP-rated animal house $\left(22 \pm 1{ }^{\circ} \mathrm{C}, 30-60 \%\right.$ relative humidity, $12 \mathrm{~h}$ light/dark cycle with light on at 06:00), and free access to tap water and standard rodent food. Treatments were performed once daily, five times a week, and lasted 3 or 4 weeks (see Table 1). The body weight of the animals was measured before each treatment.

For oral application, $\mathrm{CdCl}_{2}$ (Reanal, Hungary; purity 99.5\%) was dissolved in distilled water to $1 \mathrm{ml} \mathrm{kg}^{-1}$ b.w. administration volume and was given to the rats orally by gavage. The dose $3.5 \mathrm{mg} \mathrm{kg}^{-1}$ b.w. - was based on earlier results by Papp et al. (2003), where this dose caused slight changes in cortical electrophysiological parameters $(2 x$ and $4 \times$ higher doses had significant effects in that experiment, but the low dose was chosen to avoid overdosing in the combinations).

For intratracheal application, NPs of $\mathrm{CdO}_{2}$ with $65.6 \pm 12.4 \mathrm{~nm}$ diameter were synthesized at the Department of Applied Chemistry, University of Szeged. The NPs were suspended in $1 \%$ hydroxyethyl cellulose (HEC) dissolved in PBS ( $\mathrm{pH} 7.4)$ to have a physiologically neutral vehicle in which the NPs do not aggregate rapidly. The intratracheal dose was equal to the lower dose used in a previous experiment with $\mathrm{CdO}_{2} \mathrm{NPs}$ (Papp and Sárközi, 2008). The nanosuspension was instilled in the rats' trachea under brief diethyl ether anesthesia (for details, see Sárközi et al., 2009). The instilled volume was $1.0 \mathrm{ml} \mathrm{kg}^{-1}$ b.w.

Assuming a daily ventilation volume of $c a 0.5 \mathrm{~m}^{3} \mathrm{~kg}^{-1}$ b.w. for our rats, as suggested by the physiological data of Strohl et al. (1997), the intratracheal dose applied was the same order of magnitude as those found in industrial settings mentioned in the Introduction (Vitayavirasuk et al., 2005; Conroy et al., 1995), and the 70 and $550 \mathrm{\mu g} \mathrm{m}^{-3}$ used by Takenaka et al. (2004) in rat inhalation exposure. However, direct comparison between inhalation of NPs from the surrounding air and direct introduction of NPs into the lower airways is not realistic because of various uncertainties (e.g. exact data on absorption, unknown particle size of industrial aerosols).

\section{Behavioural Investigation}

The rats' spontaneous locomotor behavior pattern was assessed in an open field (OF) instrument 2 days after the last $\mathrm{Cd}$ application. The OF box used was of $48 \times 48 \times 40 \mathrm{~cm}$ size and equipped with two arrays of infrared beam gates at floor level and at $12 \mathrm{~cm}$ height (Conducta 1.0 System; Experimetria Ltd, Budapest, Hungary). After 20-30 min of accommodation in the test room, the animals were put into the center of the box one by one for a $10 \mathrm{~min}$ session. Counts and time of the horizontal (running), vertical (rearing) and local (grooming, etc.) activity as well as horizontal run length were calculated from the beam interruptions, where a more than $40 \mathrm{~mm}$ change in the location of the rat during a time unit of $1 \mathrm{~s}$ was interpreted as running, a smaller shift as local activity and no shift as immobility.

\section{Electrophysiological Investigation}

Electrophysiological recording was done on the day following the OF test. Preparation for recording, and the recording itself, were performed under urethane anesthesia (1000 $\mathrm{mg} \mathrm{kg}^{-1}$ i.p.). The left hemisphere was exposed, and spontaneous electrical activity (electrocorticogram, ECoG) was recorded from the primary somatosensory, visual and auditory areas for $6 \mathrm{~min}$. From this, the band spectrum according to the standard human EEG bands (delta to gamma; Kandel and Schwartz, 1985) was calculated. Then, evoked potentials (somatosensory, visual and auditory) were recorded from the same sites by applying the stimuli in trains of 50 . Somatosensory stimulation was done by square pulses (3-4 V; $0.05 \mathrm{~ms} ; 1,2$ and $10 \mathrm{~Hz}$ frequency) delivered through a pair of needles inserted into the contralateral whiskery skin. Visual stimulation was performed by flashes $(1 \mathrm{~Hz})$ of a high-luminance white LED placed directly in front of the contralateral eye of the rat. For acoustic stimulation, clicks ( $1 \mathrm{~Hz}$ ) were applied to the contralateral ear through the hollow ear bar of the stereotaxic frame. Onset latency and duration of the EPs were measured after averaging. From the tail nerve,

Table 1. Treatment scheme with group codes, doses and treatment time

Groups

Intratracheal treatment

Before oral $\mathrm{CdO}_{2} \mathrm{NPs}, 0.04 \mathrm{mg} \mathrm{kg}^{-1}$ b.w. Vehicle: HEC

\section{$\mathrm{Cd} 3 / \mathrm{V} 3$}

Cd13/V13

Cd31/V31
Treatments

Oral treatment

$\mathrm{CdCl}_{2}$, dissolved in distilled water, $3 \mathrm{mg} \mathrm{kg}^{-1}$ b.w. Vehicle: distilled water
3 weeks
3 weeks
3 weeks

Intratracheal treatment

After oral

$\mathrm{CdO}_{2} \mathrm{NPs}, 0.04 \mathrm{mg} \mathrm{kg}^{-1}$ b.w. Vehicle: HEC

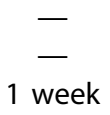

HEC, 1\% hydroxyethyl cellulose dissolved in PBS. Group codes: Cd, cadmium treated; V, vehicle treated. 
compound action potential was recorded by inserting a pair of needle electrodes at the base of the tail for stimulation, and another pair $50 \mathrm{~mm}$ distally for recording. Conduction velocity was calculated from this distance and the onset latency of the action potential. Relative refractory period was measured by double stimuli with 1-10 ms inter-stimulus interval, from the extra delay of the second potential. The complete electrophysiological work was performed by means of the software Neurosys 1.11 (Experimetria Ltd, Budapest, Hungary).

Finally, rats were sacrificed by an overdose of urethane, dissected, and organ weights were measured. Relative organ weights, on the basis of percentage body weight, were calculated.

The study was approved by the Ethical Committee for the Protection of Animals in Research of the University. During the whole procedure, the principles (based on the EU-conform Hungarian law) of the Committee were strictly followed.

\section{Statistical Evaluation}

The distribution of data was checked for normality by means of the Kolmogorov-Smirnov test. Data analysis was done by oneway ANOVA. Post hoc analysis of group differences was performed by Fisher's least significant difference test, setting the level of significance at $P>0.05$.

\section{RESULTS}

\section{Body and Organ Weights}

As shown in Fig. 1, vehicle-treated rats, including those with HEC instillation, had approximately normal body weight gain. Treatment with oral $\mathrm{CdCl}_{2}$ also had only minimal effect on the body weight. Rats receiving $\mathrm{CdO}_{2} \mathrm{NPs}$ into the trachea, however, showed weight loss during the corresponding week.

Among the relative organ weights, those of the lung, brain and liver showed significant changes (Table 2). The weight increase of the lungs was significant vs the corresponding control in both the group treated first with dissolved and then with NP Cd $(C d 31)$ and in the group receiving NP treatment first
(Cd13), but not in the group receiving dissolved Cd only. The treatment also caused an increase in the brain weight, which was slight in $C d 3$ and $C d 13$ but obvious in $C d 31$. The relative liver weight was significantly decreased in Cd31 vs own control and also vs the other treated groups.

\section{Open Field Performance}

Ambulation distance showed significant decrease in both combination groups ( $\mathrm{Cd} 31$ and $C d 13)$ compared with their corresponding controls (V31 and V13; Fig. 2A). Again, the effect in $C d 31$ was significant also in comparison to the other treated groups, and the same held true for the times spent in the four basic forms of OF activity (Fig. 2B, C). The general trend was decreased activity in all treated groups, and the change in Cd13 vs V13 was somewhat stronger than that in $C d 3$ vs V3 but remained below significance.

\section{Electrophysiological Effects}

There were no noteworthy changes in the spontaneous cortical activity. In the somatosensory EPs, significant latency increase at every stimulation frequency $(1,2$ and $10 \mathrm{~Hz})$ vs the

Table 2. Relative organ weights (related to percentage body weight); means \pm SD, $n=12$

\begin{tabular}{|c|c|c|c|}
\hline Groups & Brain & Lungs & Liver \\
\hline V3 & $0.55 \pm 0.04$ & $0.36 \pm 0.03$ & $3.29 \pm 0.33$ \\
\hline$C d 3$ & $0.57 \pm 0.03$ & $0.37 \pm 0.04$ & $3.24 \pm 0.15$ \\
\hline V31 & $0.48 \pm 0.04$ & $0.44 \pm 0.02$ & $3.49 \pm 0.25$ \\
\hline$C d 31$ & $0.55 \pm 0.05^{*}$ & $0.89 \pm 0.15^{* *+\dagger}$ & $2.96 \pm 0.15^{* \dagger \neq}$ \\
\hline V13 & $0.52 \pm 0.03$ & $0.49 \pm 0.06$ & $3.37 \pm 0.14$ \\
\hline Cd13 & $0.54 \pm 0.04$ & $0.73 \pm 0.12^{* *}$ & $3.40 \pm 0.44$ \\
\hline
\end{tabular}

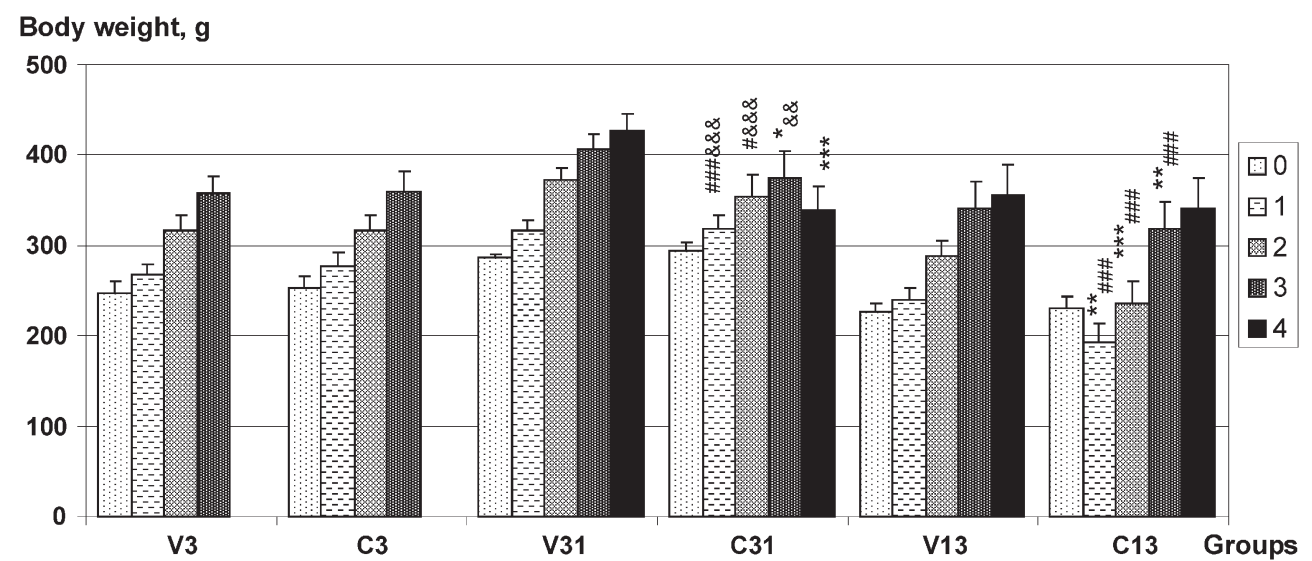

Figure 1. Time course of the control ands treated rats' body weight during the weeks of treatment (see insert). Mean \pm SD, $n=12$; the values plotted were measured at the end of the corresponding week (on Friday); week 0 data are those from the Friday preceding the first treatment. For group coding (abscissa) see Table 1. ${ }^{* * * * * *} P<0.05,0.01,0.001$ vs the corresponding control; ${ }^{*}, \# \# \#<<0.05,0.001 C d 31$ or $C d 13$ vs $C d 3 ;$; \&, \&\&\& $P<0.01,0.001$ Cd31 vs Cd13. 

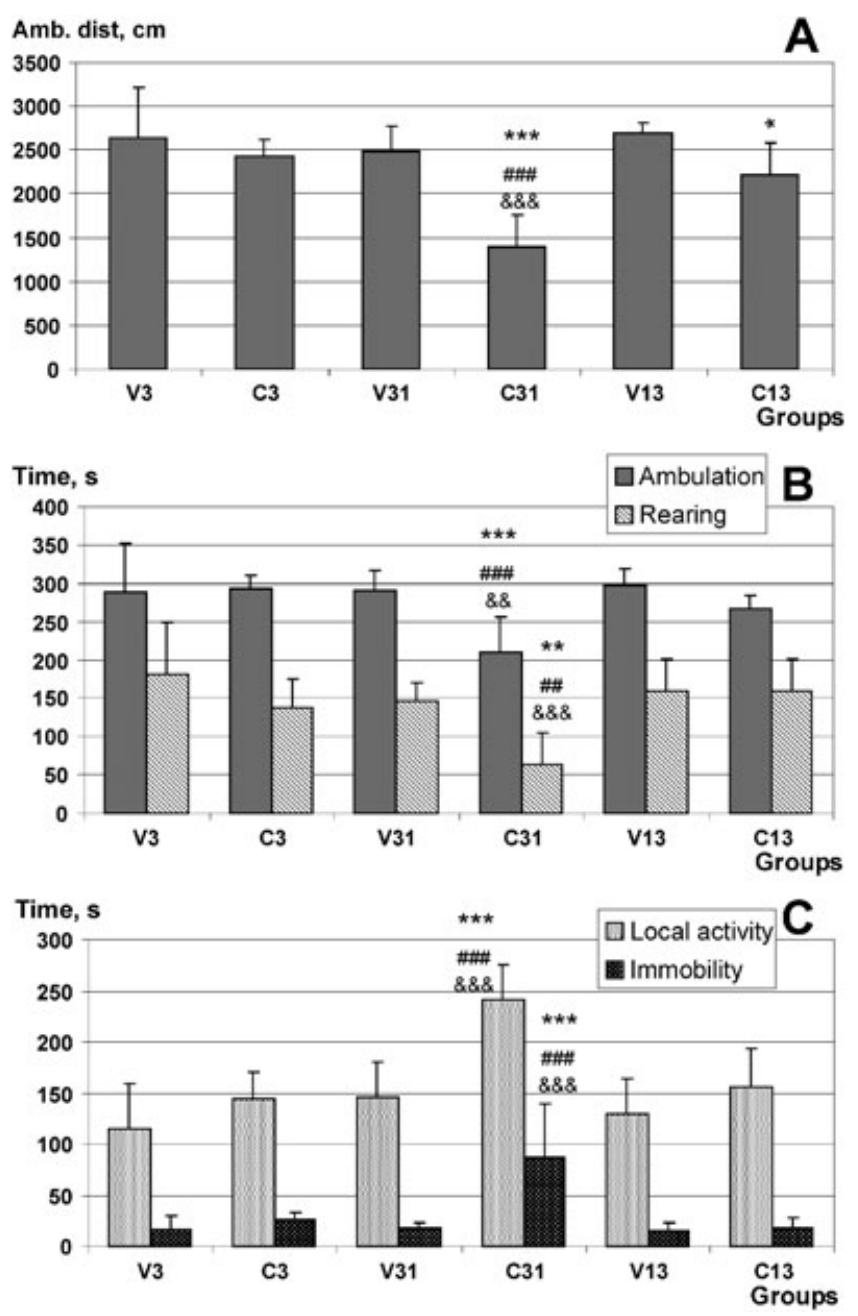

Figure 2. Open field activity of the control and treated rats at the end of treatment. (A) Ambulation distance; (B) time spent in ambulation and rearing; (C) time spent in local activity and immobility. Mean $\pm S D$, $n=12$. Groups are marked on the abscissa. Significance marking as in Fig. 1.

corresponding control was seen only in the $C d 31$ combination group (Fig. 3A). The frequency-dependent extra lengthening of latency was, on the contrary, more pronounced both in $C d 3$ and in $C d 31$ than in the controls. Duration of the somatosensory EP showed a similar trend to that seen with the latency but this remained below significance (not shown).

The visual and auditory EPs were also significantly lengthened by $C d$ application in the groups $C d 3$ and $C d 31$, but not in Cd13 (Fig. 3B). Decreased conduction velocity of the tail nerve was found in all treated groups (Fig. 4A), but here there was no difference between various treatments, unlike what was seen in the cortical evoked responses. The trend of lengthening of the relative refractory period (not shown) indicated the increased fatigability of the nerve in the treated rats (as did the frequency-dependent latency lengthening of the somatosensory EP).

\section{DISCUSSION}

The electrophysiological effects of $\mathrm{Cd}$ seen in the present work were similar to those obtained in earlier experiments with 4-12-week oral Cd exposure (Papp et al., 2003) and with intratracheal application of nanoparticulate Cd (Papp and Sárközi, 2008), which indicated that the applied Cd most probably reached the central and peripheral nervous system and was responsible for the changes. Absorption of $\mathrm{Cd}$ following inhalation has been described repeatedly. Takenaka et al. (2004) found $\mathrm{Cd}$ in the blood, liver and kidney of rats after inhalation of $40 \mathrm{~nm} \mathrm{Cd}$ oxide particles. In exposed workers, elevated urine $\mathrm{Cd}$ level was associated with reduced visuomotor performance and difficulties with concentration and stance (Viaene et al., 2000). Cases of degenerative CNS disease were also explained by the effect of Cd (Bar-Sela et al., 2001).

The toxic effects of $\mathrm{Cd}$, observed in the present work, were mostly stronger in the combination groups ( $C d 13$ and $C d 31)$ than in the group treated with dissolved $\mathrm{Cd}$ only $(\mathrm{Cd} 3)$; and were the strongest in $C d 31$ where the rats received 3 weeks oral then 1 week intratracheal exposure. The amount of $\mathrm{Cd}$ instilled was much less than that given previously per os (see Table 1), indicating a potentiating, not merely additive, effect. It can be supposed that, if during the 3 weeks of oral $\mathrm{Cd}$ treatment the blood-brain barrier was weakened (as described by Shukla et al., 1996), the Cd-containing NPs applied afterwards had higher chance of penetrating it and entering the brain. This seems to apply for the frequency-dependent lengthening of the somatosensory evoked potential and for the OF motility. A potentiation-like effect was also seen in the time course of the body weight, and in the relative brain and liver weight. In the above-mentioned experiment of Papp and Sárközi (2008), 6 weeks of intratracheal application of a 10-fold dose $\left(0.4 \mathrm{mg} \mathrm{kg}^{-1}\right)$ of similar $\mathrm{CdO}_{2} \mathrm{NPs}$ was needed to achieve significant CNS effects, which is another argument for the potentiating interaction.

Within the nervous system, $\mathrm{Cd}$ is known to affect a number of functions. $\mathrm{Cd}^{2+}$ ions block voltage-gated $\mathrm{Ca}$ channels, resulting in disturbed stimulus-dependent transmitter release and slowed conduction (Suszkiw et al., 1984), which is in line with reduced nerve conduction velocity and lengthened cortical response latency observed in our treated rats. Cd also decreases astrocytic glutamate uptake (Liu et al., 2008), which may lead to desensitization of postsynaptic receptors in afferent pathways and to suppressed cortical responses.

Open field hypomotility (reduced ambulation distance), seen first of all in the rats receiving combined treatment, was probably a consequence of disturbances to the dopaminergic system, another effect of $\mathrm{Cd}$ described in experimental work (Rajanna et al., 1990; Flora and Tandon, 1987), and in children with environmental exposure (de Burbure et al., 2006). Beyond the above-mentioned general effect of $\mathrm{Cd}$ on synaptic function, oxidative stress caused by Cd (Kumar et al., 1996) may specifically affect dopaminergic neurons (Alexi et al., 2000) and the effect of the metal on tyrosine hydroxylase (Deskin et al., 1981) may also be involved. Cd administration for several weeks was found to alter also brain acetylcholinesterase activity (Carageorgiou et al., 2004; Pari and Murugavel, 2007) which may affect both spontaneous and evoked cortical activity via the ascending reticular cholinergic activation.

The results showed that the described model of environmental and occupational $\mathrm{Cd}$ exposure based on oral and intratracheal application in rats was feasible. Its implementation indicated that such a combined exposure may have serious negative health effects in humans and hence requires further investigation. 

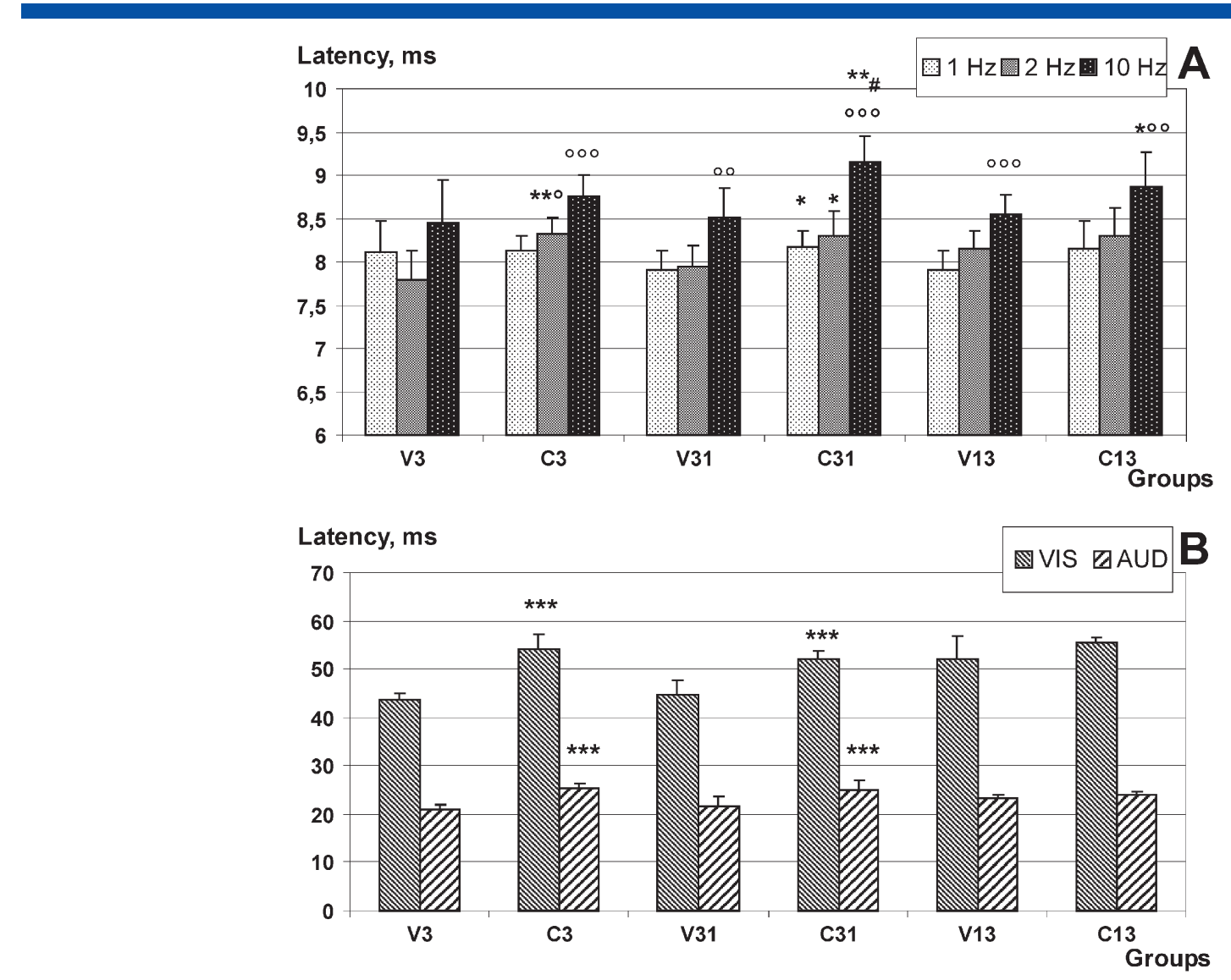

Figure 3. Onset latency of the cortical evoked potentials. (A) Somatosensory response obtained with 1,2 and $10 \mathrm{~Hz}$ stimulation (see insert); (B) visual and auditory (VIS and AUD, see insert) response. Mean \pm SD, $n=12$. Groups are marked on the abscissa. ${ }^{*} * * * * *<0.05,0.01,0.001$ vs the corresponding control at identical stimulation rate; ${ }^{\#} P<0.05 C d 31$ vs $C d 3$ at identical stimulation rate; ${ }^{\circ}$, oo, ooo $P<0.05,0.021,0.001$ value obtained at 2 or $10 \mathrm{~Hz}$ vs that at $1 \mathrm{~Hz}$ within the same group.

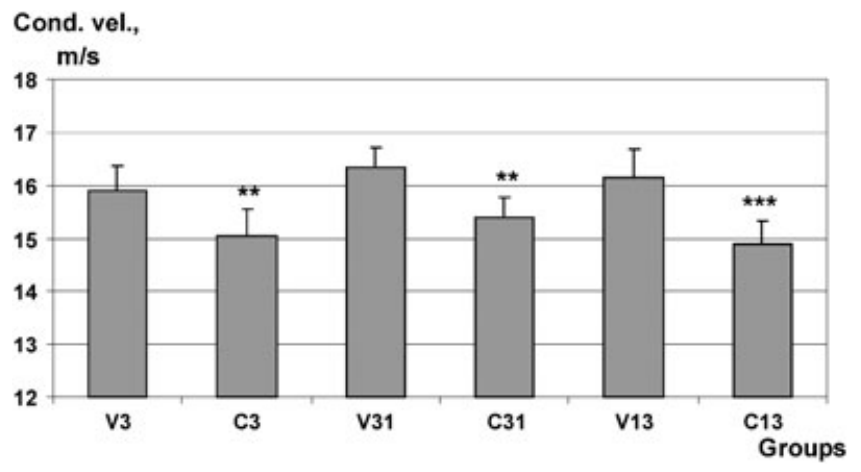

Figure 4. Conduction velocity of the tail nerve. Groups are marked on the abscissa. Mean $\pm \mathrm{SD}, n=12 . * * * * P<0.01,0.001$ vs the corresponding control.

\section{References}

Alexi T, Borlongan CV, Faull, RLM, Williams CE, Clark RG, Gluckmann PD, Hughes PE. 2000. Neuroprotective strategies for basal ganglia degeneration: Parkinson's and Huntington's diseases. Prog. Neurobiol. 60: 409-470.

Bar-Sela S, Reingold S, Richter ED. 2001. Amyotrophic lateral sclerosis in a battery-factory worker exposed to cadmium. Int. J. Occup. Environ. Health 7: 109-112.

Carageorgiou H, Tzotzes V, Pantos C, Mourouzis C, Zarros A, Tsakiris S. 2004. In vivo and in vitro effects of cadmium on adult rat brain total antioxidant status, acetylcholinesteersae, $\left(\mathrm{Na}^{+}, \mathrm{K}^{+}\right)$-ATPase and $\mathrm{Mg}^{2+}$ ATPase activities: protection by L-cysteine. Basic Clin. Pharmacol. Toxicol. 94: 112-118.

Chaney RL, Reeves PG, Ryan JA, Simmons RW, Welch RM, Angle JS. 2004. An improved understanding of soil $\mathrm{Cd}$ risk to humans and low cost methods to phytoextract $\mathrm{Cd}$ from contaminated soils to prevent soil Cd risks. Biometals 17: 549-553.

Conroy LM, Lindsay RM, Sullivan PM. 1995. Lead, chromium and cadmium emission factors during abrasive blasting operations by bridge painters. Am. Ind. Hyg. Assoc. J. 56: 266-271.

de Burbure C, Buchet JP, Leroyer A, Nisse C, Haguenoer JM, Mutti A, Smerhovsky Z, Cikrt M, Trzcinka-Ochocka M, Razniewska G, Jakubowski M, Bernard A. 2006. Renal and neurologic effects of cadmium, lead, mercury, and arsenic in children: Evidence of early effects and multiple interactions at environmental exposure levels. Environ. Health Persp. 114: 584-590.

Deskin R, Bursian SJ, Edens FW. 1981. An investigation into the effects of manganese and other divalent cations on tyrosine hydroxylase activity. NeuroToxicol. 2: 75-81.

Elder A, Gelein R, Silva V, Feikert T, Opanashuk L, Carter J, Potter R, Maynard A, Ito Y, Finkelstein J, Oberdörster G. 2006. Translocation of ultrafine manganese oxide particles to the central nervous system. Environ. Health Persp. 114: 1172-1178.

Elinder CG, Kjellström T, Lind B, Linnman L, Piscator M, Sundstedt K. 1983. Cadmium exposure from smoking cigarettes: variations with time and country where purchased. Environ. Res. 32: 220-227.

Fern R, Black JA, Ransom BR, Waxman SG. 1996. Cd(2+)-induced injury in CNS white matter. J. Neurophysiol. 76: 3264-3273.

Flora SJ, Tandon SK. 1987. Effect of combined exposure to cadmium and ethanol on regional brain biogenic amine levels in the rat. Biochem. Int. 15: 863-871. 
Galal-Gorchev H. 1991. Dietary intake of pesticide residues, cadmium, mercury and lead. Food Addit. Contam. 8: 793-806.

Goering PL, Waalkes MP, Klaassen CD. 1995. Toxicology of cadmium. In Toxicology of Metals: Biological Aspects. Handbook of Experimental Pharmacology, Vol. 115, Goyer RA, Cherian MG (eds). Springer: New York; 189-213.

Kandel ER, Schwartz JH. 1985. Principles of Neural Science. Elsevier, New York; 643-644.

Kreyling WG, Semmler-Behnke M, Möller W. 2006. Ultrafine particle-lung interactions: does size matter? J. Aerosol Med. 19: 74-83.

Kumar R, Agarwal AK, Seth PK. 1996. Oxidative stress-mediated neurotoxicity of cadmium Toxicol. Lett. 89: 65-69.

Leroyer A, Hemon D, Nisse C, Auque G, Mazzuca M, Haguenoer JM. 2001. Determinants of cadmium burden levels in a population of children living in the vicinity of nonferrous smelters. Environ. Res. $\mathbf{8 7}$ 147-159.

Liu YP, Yang CS, Tzeng SF. 2008. Inhibitory regulation of glutamate aspartate transporter (GLAST) expression in astrocytes by cadmiuminduced calcium influx. J. Neurochem. 105: 137-150.

Oberdörster G, Finkelstein JN, Johnston C, Gelein R, Cox C, Baggs R, Elder AC. 2000. Acute pulmonary effects of ultrafine particles in rats and mice. Res. Rep. Health Eff. Inst. 96: 5-74; discussion 75-86.

O'Callaghan JP, Miller D. 1986. Diethyldithiocarbamate increases distribution of cadmium to brain but prevents cadmium-induced neurotoxicity. Brain Res. 370: 354-358.

Okuda B, Iwamoto Y, Tachibana H, Sugita M. 1997. Parkinsonism after acute cadmium poisoning. Clin. Neurol. Neurosurg. 99: 263-265.

Papp A, Sárközi L. 2008. Consequences of subacute intratracheal exposure of rats to cadmium oxide nanoparticles: electrophysiological and toxicological effects. In Metal Elements in Environment, Medicine and Biology, Vol. VIII. Silaghi-Dumitrescu I, Garban Z, Dragan P (eds). Eurobit, Timisoara; 67-72.

Papp A, Nagymajtényi L, Dési I. 2003. A study on electrophysiological effects of subchronic cadmium treatment in rats. Environ. Toxicol. Pharmacol. 13: 181-186.
Pari L, Murugavel P. 2007. Diallyl tetrasulfide improves cadmium induced alterations of acetylcholinesterase, ATPases and oxidative stress in brain of rats. Toxicology 234: 44-50.

Rajanna B, Hobson M, Boykin M, Chetty CS. 1990. Effects of chronic treatment with cadmium on ATPases, uptake of catecholamines, and lipid peroxidation in rat brain synaptosomes. Ecotoxicol. Environ. Saf. 20: $36-41$.

Sárközi L, Horváth E, Kónya Z, Kiricsi I, Szalay B, Vezér T, Papp, A. 2009. Subacute intratracheal exposure of rats to manganese nanoparticles: behavioral, electrophysiological and general toxicological effects. Inhal. Toxicol. 21(S1): 83-91.

Shukla A, Shukla GS, Srimal RC. 1996. Cadmium-induced alterations in blood-brain barrier permeability and its possible correlation with decreased microvessels antioxidant potential in rat. Hum. Exp. Toxicol. 15: 400-405.

Strohl KP, Thomas AJ, St. Jean P, Schlenker EH, Koletsky RJ, Schork NJ. 1997. Ventilation and metabolism among rat strains J. Appl. Physiol. 82:317-323.

Suszkiw J, Toth G, Murawsky M, Cooper GP. 1984. Effects of $\mathrm{Pb}^{2+}$ and $\mathrm{Cd}^{2+}$ on acetylcholine release and $\mathrm{Ca}^{2+}$ movements in synaptosomes and subcellular fractions from rat brain and torpedo electric organ. Brain Res. 323: 31-46.

Takenaka S, Karg E, Kreyling WG, Lentner B, Schulz H, Ziesenis A, Schramel P, Heyder J. 2004. Fate and toxic effects of inhaled ultrafine cadmium oxide particles in the rat lung. Inhal. Toxicol. 16(suppl. 1): 83-92.

Viaene MK, Roels HA, Leenders J, De Groof M, Swerts LJVC, Lioson D, Masschelein R. 1999. Cadmium. A possible etiological Factor in peripheral polyneuropathy. NeuroToxicol. 20: 7-16.

Viaene MK, Masschelein R, Leenders J, De Groof M, Swerts LJ, Roels HA. 2000. Neurobehavioural effects of occupational exposure to cadmium: a cross sectional epidemiological study. Occup. Environ. Med. 57: 19-27.

Vitayavirasuk B, Junhom S, Tantisaeranee P. 2005. Exposure to lead, cadmium and chromium among spray painters in automobile body repair shops. J. Occup. Health 47: 516-522. 